\section{SCLEROTIC THERAPY IN PRACTICE I.}

By R. Rowden Foote, M.R.C.S., L.R.C.P., D.R.C.O.G.

(Physician-in-charge, Injection Clinic, Royal Waterloo Hospital for Children and Women)

There is still a wide field for the practitioner who wishes to treat a variety of conditions by means of the injection of sclerotic solutions. The purpose of this short series of articles is to discuss those conditions which are, and those which are not, suitable cases for such treatment. A proper knowledge of the subject will do much to lighten the routine of general practice, but it is essential that those interested should endeavour, for a period of time, to attend a clinic devoted to the subject. The two cardinal rules of success are that a proper selection of cases should first be made, and that a careful technique should be employed. There are many techniques and solutions in use for the various conditions which will be discussed, but it is better to become proficient in one selected method than to have a superficial knowledge of many. An efficient remedy or technique in the hands of one operator may otherwise become a dangerous weapon in those of another. Sclerotic therapy, like good wine, needs no bush. It has a very definite place in treatment and can, in properly selected cases produce far more successful results than can be shown by surgery. Anyone observing the end result of a properly injected hydrocele cannot fail to agree with this statement? Again, the injection treatment applied to certain cases of haemorrhoids is surely more radical than is the accepted surgical procedure ... the knife, clamp, or cautery being limited to the pile area only, whereas the lax mucosa above can only be reached by the high injection of a sclerosing medium.

Sclerotic therapy need not encroach on the work of the surgeon, and it is hoped that the ensuing article will do something towards clarifying this statement. Many cases will be "borderline," but later surgical treatment is not negatived by preceding injection treatment. There is no doubt that the subject of proper injection treatment is not sufficiently dramatic for many students . . . and it is not uncommon for a house-surgeon "to know all about pile and vein injection" after the treatment of a few cases. Such mentalities are responsible for haphazard, slovenly, sporadic and inefficient injections, which have in very many cases been received by the patient prior to arrival at a special clinic. Such treatment and the faulty selection of cases brings a valuable method intoڤ disrepute.

In passing, it is of interest to note that the doctor-patient is of common occurrence-with. him, the needle is frequently more acceptable than $\underset{\mathrm{F}}{\overrightarrow{0}}$ is the knife, and I was interested recently to ? observe how many of the staff of a hospital had $\frac{}{5}$ received injections for their piles! The centenary $\frac{\bar{\sigma}}{\bar{n}}$ of the discovery of the hypodermic needle is with $\vec{\sigma}$ us this year, and ever since De Rynd made this 0 great gift to science, sclerotic therapy of one sort is or another has been with us. The treatment has $\vec{\circ}$ undergone several waves of popularity and the reverse. In the early days enthusiastic pioneers $\vec{\omega}$ injected solutions of pure carbolic, iron perchloride, $\frac{\Omega}{\circ}$ etc. Sloughs and sepsis were the rule, and it waso not until the early part of this century that the therapy became established on a firm basis. Since Sicard's discovery of sodium salicylate for the injection treatment of varices, new solutions and fresh techniques have occurred, but much still remains for research, and ideal solutions have stillo to be found. Some may feel that this adds interest to a treatment which is a proven useful remedy. The following is a list of conditions which will? prove suitable for injection therapy. In each separate condition certain selective factors need to be present before saying that surgery or alted $\overrightarrow{0}$ native treatment may be preferable. These or factors will be pointed out when the practical side of treatment is under discussion.
I. Idiopathic Hydrocele
2. Haemorrhoids
3. Varicose Veins
4. Pruritus Ani
5. Ganglion
6. Naevus
7. Anal Fissure
8. Bursae.

It is to be noted that both hernia and varicocele $\frac{3}{6}$ are not in the list. This is done with purpose, 3 . since I am firmly of the opinion that no good can come from injection treatment. Those readers 3 who are interested in the technique of sclerosiso in these conditions may find an excellent description by Riddle in Injection Treatment (I940). Ogilvie in 1937 writes that he considers the injection treatment of hernia as being "a throwback to $N$ a mediaeval method," and I agree with this statement.

The injection treatment of certain cystic condi- $\omega$ tions of the breast, etc., is also not discussed, since this therapy is not in the range of general practice.

The injection treatment of fistula is one which $\stackrel{?}{+}$ is very strongly advocated by Kasper Blond ${ }_{0}^{0}$ (I940). He claims considerable success in a large $\frac{\widetilde{\Phi}}{\mathrm{D}}$ 
series of cases. I have no real experience of such treatment, and find it difficult to see how injections may influence a fistulous track. However, it is to be hoped that others may be able to obtain the results of this author, since the alternative of surgery is of a drastic nature.

What results may we expect from the injection treatment of the eight conditions listed above?

\section{Hydrocele.}

I place hydrocele right at the top of the list, since it is very seldom that an absolute cure cannot be obtained by one or more simple injections. Occasionally a very old large hydrocele, with a tough fibrous sac, may prove too resistant to sclerotic media. The very large majority of cases, however, are cured easily, the end result being far superior to anything that can be offered by surgery.

\section{Haemorrhoids.}

And what can be said regarding the cure of piles by injection? A faulty selection of cases for this therapy has allowed the critics to enlarge unduly on the subject of recurrence rates, but given a correct selection of cases, pile injection is a most valuable treatment. Much may be learned from the study of recent statistics regarding the rival merits of surgery and injection. Recent reports from St. Mark's Hospital for Diseases of the Rectum, taken over a period of five years, give us the following facts. In piles of the first degree $98 \cdot 3$ per cent of cases remain cured after a five-year period, when injection treatment only had been administered. Certainly I5 per cent required a few further injections in from one to three years after treatment, but this does not detract from these most excellent figures.

These statistics go on to show that the cure rate diminishes as the pile condition becomes more advanced. Piles of the second degree giving a 68 per cent cure rate from injections, and those of the third degree a mere 3 I per cent cure rate.

This is the number of cures however, and no mention has been made of the very real relief from symptoms that certainly occurred with a large number of patients. Such relief may have lasted for a few years only . . . but could be renewed from a repetition of simple and painless treatment? Such "recurrences" should be suitable candidates for a periodic "servicing." I can see no reason why the patient should object to this procedure any more than he would to regular dental attendance-in fact it should be a less painful visit? Kilbourne (I934), in America, collected the statistics from the files of numerous proctologists. $\mathrm{He}$ analysed the results obtained from both surgical and injection treatment. His researches covered some sixty-two thousand odd $\underset{3}{3}$ cases, and his findings are of real interest. $\mathrm{He} \stackrel{\mathbb{D}}{\circ}$ found that 5 per cent of cases recurred when $c$. treated by surgical methods, whereas from Io to $\Rightarrow$ I5 per cent of recurrences occurred when injection $\stackrel{\vec{F}}{+}$ treatment only had been given.

In the 26,000 injected cases there were no deaths, whereas in the 36,000 patients treated by $\frac{\bar{\omega}}{\vec{D}}$ surgical means eleven died. Rectal stricture was $\stackrel{\varnothing}{\varrho}$ ten times commoner when surgical means of cure had been employed, and haemorrhage more than $\vec{\circ}$ twice as frequent a complication. These statistics read in conjunction with the following well- $\vec{\omega}$ recognised advantages of injection treatment are $\stackrel{\circ}{\circ}$ of interest? The treatment is ambulatory, and $\overparen{D}$ does not interfere with the patients' work. No 3 anaesthetic risk is present. The treatment is cheaper, and post-operative pain is avoided. $\overrightarrow{\mathrm{j}}$ Complications are few if proper technique is $\mathscr{O}_{0}$ employed.

In order to select cases properly for injection treatment, experience is very necessary. Age, $\stackrel{ }{工}$ occupation, general health, and degree of pile $\vec{c}$ prolapse all have to be considered. No case of external piles should ever be submitted to injection. With this exception, it should be noted $₹$ that few cases of piles will not be benefited bg $\overrightarrow{0}$ sclerotic treatment, but that hopes of permanen进 $\mathrm{c}$ cure from one series of injections should only bes. offered to patients suffering from first degree haemorrhoids. All cases considered to be bad operative risks and all those who have refused surgery should, however, be given the benefit of $\stackrel{\circ}{\varnothing}$ injections. Lastly, unless the operator has the $\triangle$ requisite knowledge as to which type of pile $\overrightarrow{\bar{a}}$ should be treated by the sclerotic method and which should not be so treated, he is not justified in undertaking injection therapy.

\section{Varicose Veins.}

Of what use is injection treatment in these prevalent afflictions?

There is no Ioo per cent treatment for the "Varicose State."

At the present time they may be treated by $D$ conservative supportive measures, by surgery alone, by injections, or by a combination of these $\mathrm{N}$ two latter procedures.

Ten years ago injection treatment was being given $\tilde{O}$ to all types of varices, and was considered to be $N$ the end-all of therapy. The haphazard selection of cases for this form of treatment produced a high 0 recurrence rate, and as a result we now run the $\overparen{D}$ risk of the pendulum swinging too far towards the $\stackrel{\oplus}{+}$ surgical side once again. Some surgeons now say $t$ that all cases of varix should be submitted to 
surgery, the only exceptions being in those minor cases in which treatment is being given for cosmetic reasons. I consider that this view is as misleading as was the wholesale injection methods of a decade ago. There is a halfway house, and experience in the proper selection of cases for the knife or needle may be acquired by the study of a sufficiency of cases. I shall endeavour to clarify the position in a subsequent article, but in passing I feel it only right to emphasise the point that surgery should be limited to those cases in which there is a gross valvular deficiency as shown by the Trendelenberg test. Also the practitioner should satisfy himself that the patient is a safe operative risk. Even in the hands of experts there is a definite mortality from the operation of high ligation, or, as it is better called, "high resection." Embolism and wound infection occur even in those lists of cases as published by experts such as Ochsner and Faxon.

Injury to the femoral artery, ligature of the femoral vein, secondary haemorrhages, and wound sepsis have been brought to the author's notice on several occasions. Those interested will be well advised to read an excellent article by Lawrence N. Atlas (I943), in which he ably describes some of the hazards connected with the treatment of varices. He describes many cases of death, haemorrhage, and massive deep-vein thrombosis resulting from the retrograde injection of sclerosants after high internal saphenous vein resection. He also points out some of the risks of simple injection which, however, do not compare in severity with those produced by surgery.

On the other hand, given proper technique, injections are safe. McPheeters and Rice attributed only seven deaths to treatment by injection in a group of 53,000 cases. At the Royal Waterloo Hospital I can find no record of a death during the past twenty years, during which time a larger number than those published by McPheeters and Rice must have been given.

Yeomans (I939), referring to the operation of high ligation of the internal saphenous vein, states, "I feel that it is still a procedure the use of which should be limited to those patients in whom the added advantages greatly outweigh the added risks." McPheeters and Anderson (I939) state, "In the early cases of varicose veins, or in any case in which the vein in the groin is not larger than $\mathrm{I} \frac{1}{2} \mathrm{~cm}$. in diameter, we may expect a good result from injections alone."

The recurrence of symptoms is another interesting angle to review.

Faxon (I933) quotes a series of cases which had received injection treatment, and in which recanalisation had occurred in as many as 63 per cent of the total number injected. Fifty-nine per cent of these cases which had recurred showed ngs return of symptoms, and a further 34 per cent experienced a moderate degree of relief. In othe words, 93 per cent of the failures were either symptom-. less or else improved! His further analysis showe that 38 per cent of varicose ulcers had remaine $\$$ firmly healed in spite of the re-canalisation of theis varices. Although I have no figures, I have noted a similar satisfactory state of affairs wit many of the "recurrences" in my own practicen The thickened veins, although re-canalised, are able to stand up to their job better than in their. pre-injection state, and in these cases the patien ${ }_{\text {. }}$ often asks for a further series of injections. It is true that a fair number of cases do recur by recanale isation, but before this has taken place relief has occurred from the sclerosis, and a further course. of injections is not inacceptable to the patientiv When first seeing the sufferer the doctor should explain the present state of affairs regarding the respective merits of the treatments, and give hig patient an understanding of the possibilities of recurrence.

As stated previously, there is still no "Ioo per cent" satisfactory cure of varices, and some cases show a tendency to recur whatever type of treat ment is given.

I am satisfied that there is still a very wide figltb for the treatment of varices by injection, and t通at if the physician is careful and follows the "emiti vein" technique whenever practicable, he will $\$$ doing useful work. He must use his experience and judge every case on its merits as to whethe surgery should prove the better procedure, bu should not allow the present-time wave of surgical

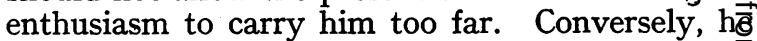
should not attempt the injection of large vein with incompetent valves. He must leave thes? to the surgeon unless the procedure is refused b. the patient.

\section{Pruritus Ani.}

Symptomatic relief may be given to most casê in which organic causation has been excluded. The results compare favourably with those olf tained by the many treatments, such as X-ray which are employed for this condition. The fre quently co-existing condition of piles must be deald with at the same time, and is an important factor in the eradication of the irritation.

\section{Ganglion.}

This condition may be cured by means of inje६ tion in the majority of cases. Sarma (I946) obtained a 78 per cent cure absolute rate in a large series of cases. Surgery may involve a much 
larger operation than was considered necessary prior to treatment, and complications such as nerve injury are known to occur. For this reason alone it is well worth while to offer patients what is tantamount to an eighty per cent chance of cure by means of sclerotic treatment, before submitting them to more drastic measures?

\section{Naevus:}

The problem of the injection treatment of naevus must exclude the naevus vinosus (port wine stain). The end results of treatment of the other forms of naevus compare favourably with the other recognised forms of therapy.

\section{Anal Fissure.}

The recent and uncomplicated type of anal fissure usually heals with a few injections. Piles are frequently an associated condition, and in order to prevent a recurrence of the fissure these have to be treated at the same time.

\section{Bursae.}

Pre-patellar and olecranon bursae may usually be cured by means of sclerotic injections. Bursae with thickened and fibrotic sac walls are better treated surgically.

To sum up, all cases for sclerotic treatment need to be properly selected, and extravagant claims of cure must be resisted. The possibility of recurrence should be discussed with the patient, and he should be offered the advantage of a periodic overhaul, in the same manner as does the dentist. Such "servicing" at any rate offers a safe method for the relief of his symptoms . . . and as every general practitioner will fully appreciate, it is these symptoms, and not the perfection of the cure, which interests the average patient.

Much of interest has been written regarding the aetiology of the varicose state, and doubtless in the future neither the needle nor knife will be required for the relief of the various evils produced. In my book on injection treatment I refer to "Varicosity Factors," which term is intended to cover the many causes of varices. Congenital, postural, and phlebitic theories are all well accepted, and Sicard's theory regarding endocrine disturbance has stood the test of time. However⿳亠口冋口. there is no space in which to pursue this interesting side of the subject, since the practical angle onl遍 is under consideration. Kasper Blond (I940) hasan interesting chapter in his book, which discusses. the aetiology of haemorrhoids. He compares the complications of piles with those of varicose veins, and discusses the "Varicose syndrome op the rectum." His theories form a valuable pointer towards improved therapy, and are well worth reading.

\section{Summary}

I. There is still a wide field for injection treat ment. In many cases this form of therapy is superior to that offered by surgery.

2. Cases for injection treatment must be cor rectly selected.

3. The technique of injection should be studied in a clinic devoted to the subject.

4. Prognosis must not be too definite. The cure may require a periodical survey of the patiento

5. In the case of varicose veins, recurrence of the veins from recanalisation does not necessarily produce a-return of symptoms.

6 . Some percentage cure rates are presented.

7. Subsequent articles will endeavour to present the practical details of the injection treatment $\overrightarrow{0} \overrightarrow{\mathrm{fo}}$ each separate condition already discussed.

\section{REFERENCES}

I. BLOND, KASPER (1940), Haemorrhoids and their Treatment (Johमु Wright \& Sons, Ltd.)

2. FAXON, W. H. (1933), "End Results in the Injection Treatmenמ of Varicose Veins: a Report on 314 cases," New England, J. Med.D 208, 357 .

3. FOOTE, R. ROWDEN (1944), Varicose Veins, Haemorrhoids and Other Conditions. Their Treatment by injection (H. K. Lewis \& Co. London).

4. KILBOURNE, N. J. (1934), Internal Haemorrhoids; Comparative

value of Treatment by Operation and by Injection Methods. BI," Munchen med. Wchnzhr., 85, 9 .

6. BA," Munchen med. Wchnzhr., 85, 9. Treatment of Varicose Veins," Journ. Surg. Gynal. and Obst., 77

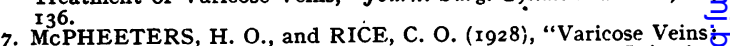
Complications Direct and Associated, following the Injection Treatment," J. Amer. Med. Ass., 91, rogr.

8. MAINGOT, R. H. (I932), Injection Treatment of Varicose Veinsi Haemorrhoids and Other Conditions (London, H. K. Lewis \& $\mathrm{Co}$.). RIDDLE, P. (1940), Injection Treatment (Philadelphia, W. BD Saunders Co.).

Io. SARMA, P. J. (1940), "The Injection Treatment of Ganglions and Bursae; Indications and Limitations," Surg. Clin. N. Amer.? $20,135$.

II. SICARD, J. A., and GAUGIER, L. (I93I), Le Traitement des Varices par les Injections Locales Sclerosantes, 3rd Edit., Paris Masson. par les Injections Locales Sclorosantes, ard Edit., Paris. YEOMANS, F. C. (1939), Sclerosing Therapy (London, Baillièreฮ Tindall \& Cox). 